\title{
Avaliação da população bacteriana nas superfícies das macas de um Hospital Universitário de Pernambuco
}

\author{
Evaluation of the bacterial population on the surfaces of stretchers of a University Hospital in
}

Pernambuco

Evaluación de la población bacteriana en las superficies de camillas de un Hospital Universitario de Pernambuco

Wesllandson Kennedy dos Santos Souza

ORCID: https://orcid.org/0000-0002-0083-6364 Universidade Federal do Vale do São Francisco, Brasil E-mail: wesllandson@hotmail.com

Mirthes Maria Rodrigues Santana ORCID: https://orcid.org/0000-0002-7087-7145 Universidade Federal do Vale do São Francisco, Brasil E-mail: mirthes-mari@hotmail.com

Rafael Cunha Libório

ORCID: https://orcid.org/0000-0003-0148-1793 Universidade Federal do Vale do São Francisco, Brasil E-mail: rafael.liborio@ebserh.gov.br

Humberto Artur Silva Santos

ORCID: https://orcid.org/0000-0001-8525-1113

Universidade Federal do Vale do São Francisco, Brasil E-mail: humberto.santos@ebserh.gov.br

Katia Regina de Oliveira

ORCID: https://orcid.org/0000-0002-3049-0827 Universidade Federal do Vale do São Francisco, Brasil E-mail: katia.regina@ebserh.gov.br

Marcos Duarte Guimarães

ORCID: https://orcid.org/0000-0002-9458-5649 Universidade Federal do Vale do São Francisco, Brasil E-mail: marcos.guimaraes@ebserh.gov.br

Ricardo Kenji Shiosaki

ORCID: https://orcid.org/0000-0001-9338-5824 Universidade de Pernambuco, Brasil E-mail: ricardo.shiosaki@upe.br Carine Rosa Naue

ORCID: https://orcid.org/0000-0003-4215-3606 Universidade Federal do Vale do São Francisco, Brasil E-mail: carine.naue@ebserh.gov.br

\begin{abstract}
Resumo
As infecções hospitalares (IH) são um grande problema de saúde pública mundial e estão relacionadas a fatores como a utilização inadequada de antibióticos, procedimentos invasivos, higienização inadequada dos objetos e das mãos dos profissionais da saúde. O presente estudo teve como objetivo isolar, identificar e analisar o perfil de resistência antimicrobiana das bactérias presentes nas superfícies das macas de um Hospital Universitário de Pernambuco. Tratase de um estudo descritivo-exploratório com abordagem quantitativa realizado em duas salas de um Hospital Universitário. A coleta dos swabs foi realizada em 60 macas nas seguintes superfícies: a) Grade esquerda; b) Grade direita; c) Centro superior e d) Centro inferior. As amostras das superfícies foram coletadas, utilizando-se um molde de papel filtro de área de $4 \mathrm{~cm}^{2}$ e swabs embebidos em solução salina $0,9 \%$ estéril. Após a passagem do swab, nas superfícies, eles foram armazenados em tubo contendo $5 \mathrm{~mL}$ meio líquido BHI (Brain Heart Infusion). Em seguida, as amostras foram transportadas para o Laboratório de Análises Clínicas/ Setor Microbiologia, onde foram realizadas as análises microbiológicas e antibiogramas. O total de isolados bacterianos nas superfícies das macas foi de 562, independentemente do local amostrado, sendo 11 espécies possíveis causadoras de infecções hospitalares, entre elas: Staphylococcus aureus, Acinetobacter baumannii, Klebsiella pneumoniae e Escherichia coli. Com relação ao perfil de resistência, alguns desses microrganismos apresentaram $100 \%$ de resistência aos antibióticos testados. Esses
\end{abstract}


resultados permitem concluir que as macas analisadas podem reservar bactérias resistentes que favorecem as IHs e necessitam de protocolos de higienização.

Palavras-chave: Bactérias Gram-negativas; Emergência; Farmacorresitência bacteriana; Infecções bacterianas.

\begin{abstract}
Abstrac
Hospital infections (NI) are a major public health problem worldwide and are related to factors such as the inappropriate use of antibiotics, invasive procedures, inadequate hygiene of objects and the hands of health professionals. The present study aimed to isolate, identify and analyze the antimicrobial resistance profile of bacteria present on the surfaces of stretchers of a University Hospital in Pernambuco. This is a descriptive-exploratory study with a quantitative approach carried out in two rooms of a University Hospital. Swab collection was performed on 60 stretchers on the following surfaces: a) Left grid; b) Right grid; c) Upper center and d) Lower center. Surface samples were collected using a filter paper mold with an area of $4 \mathrm{~cm}^{2}$ and swabs soaked in $0.9 \%$ sterile saline solution. After passing the swab on the surfaces, they were stored in a tube containing $5 \mathrm{~mL}$ BHI liquid medium (Brain Heart Infusion). Then, the samples were transported to the Clinical Analysis Laboratory/Microbiology Sector, where microbiological and antibiogram analyzes were performed. The overall of bacterial isolates on the litter surfaces was 562, regardless of the sampled location, with 11 species being possible cause of hospital infections, including: Staphylococcus aureus, Acinetobacter baumannii, Klebsiella pneumoniae and Escherichia coli. Regarding the resistance profile, some of these microorganisms showed $100 \%$ resistance to the antibiotics tested. These results allow us to conclude that hospital stretchers can reserve resistant bacteria that favor HIs and require hygiene protocols. Keywords: Gram-negative bacteria; Emergency; Bacterial pharmaco-resistance; Bacterial infections.
\end{abstract}

\title{
Resumen
}

Las infecciones hospitalarias (IN) son un importante problema de salud pública a nivel mundial y están relacionadas con factores como el uso inadecuado de antibióticos, procedimientos invasivos, higiene inadecuada de los objetos y de las manos de los profesionales de la salud. El presente estudio tuvo como objetivo aislar, identificar y analizar el perfil de resistencia antimicrobiana de bacterias presentes en las superficies de camillas de un Hospital Universitario de Pernambuco. Se trata de un estudio descriptivo-exploratorio con abordaje cuantitativo realizado en dos salas de un Hospital Universitario. La recolección de hisopos se realizó en 60 camillas en las siguientes superficies: a) Rejilla izquierda; b) Cuadrícula derecha; c) Centro superior yd) Centro inferior. Las muestras de superficie se recogieron utilizando un molde de papel de filtro con un área de $4 \mathrm{~cm}^{2}$ y hisopos empapados en solución salina estéril al $0,9 \%$. Después de pasar el hisopo por las superficies, se almacenaron en un tubo que contenía $5 \mathrm{~mL}$ de medio líquido BHI (Infusión de cerebro y corazón). Luego, las muestras fueron transportadas al Laboratorio de Análisis Clínicos / Sector de Microbiología, donde se realizaron análisis microbiológicos y antibiograma. El general de aislamientos bacterianos en las superficies de la cama fue de 562, independientemente de la ubicación de la muestra, con 11 especies como posibles causantes de infecciones hospitalarias, que incluyen: Staphylococcus aureus, Acinetobacter baumannii, Klebsiella pneumoniae y Escherichia coli. En cuanto al perfil de resistencia, algunos de estos microorganismos mostraron una resistencia del $100 \%$ a los antibióticos probados. Estos resultados nos permiten concluir que las camillas hospitalarias pueden reservar bacterias resistentes que favorecen los IH y requieren protocolos de hygiene.

Palabras clave: Bacterias Gram-negativo; Emergencia; Farmacorresistencia bacteriana; Infecciones bacterianas.

\section{Introdução}

Diante dos avanços da tecnologia e da ciência é notável a melhoria da assistência em saúde no ambiente hospitalar, no entanto, grandes problemas antigos continuam a preocupar e se agravar significativamente, como é o caso das infecções hospitalares (IHs). Essas infecções estão associadas a fatores como problemas no processo de desinfecção de materiais, utilização inadequada de antimicrobianos e procedimentos invasivos sem as devidas práticas assépticas, fatores estes que apontam a IHs como um dos maiores problemas da saúde pública (Silva et al., 2016).

De acordo com Michelin e Fonseca (2018), IH é aquela adquirida pelo paciente no ambiente hospitalar, manifestandose durante o internamento ou até mesmo após sua alta, desde que seja associada aos procedimentos assistenciais e/ou período de hospitalização.

A IH é considerada o evento adverso mais comum durante o internamento, principalmente em países subdesenvolvidos que sofrem, contudo, de problemas estruturais e déficits no processo de higienização. Ela é responsável também pelo prolongamento da internação, gerando aumento de custos e das taxas de morbidade e mortalidade nas instituições (Fracarolli \& Marziale, 2019). Nos países desenvolvidos, as IHs também são um grande problema. Nos Estados Unidos da América (EUA), por exemplo, estima-se que 1,7 milhão de pacientes recebem esse diagnóstico por ano, com taxa de 
mortalidade próxima a 100 mil, totalizando custos acima de U \$30 milhões por ano (Leoncio et al., 2018). A nível nacional, a taxa de IH é de $22,8 \%$, valor muito acima dos apresentados por países europeus que apresentam taxas menores que $9 \%$ (Sousa et al., 2017).

As infecções mais comuns que estão presentes nos serviços de saúde são as infecções do trato urinário (ITU), às pneumonias associadas à ventilação mecânica, as da corrente sanguínea e as infecções cirúrgicas (Fracarolli \& Marziale, 2019). A partir de um estudo desenvolvido de 2000 a 2016, os microrganismos patogênicos causadores dessas infecções foram, predominantemente, Pseudomonas aeruginosa, Staphylococcus aureus, Acinetobacter baumannii, Klebsiella pneumoniae, Acinetobacter spp., Pseudomonas spp, Klebsiella spp, Staphylococcus spp, Staphylococcus, Proteus mirabilis, MRSA (Staphylococcus aureus Meticilina Resistente), Enterobacter aerogenes e Citrobacter koseri (Costa et al., 2019).

Dentro do ambiente hospitalar e seus vários setores, pode-se destacar a Unidade de Terapia Intensiva (UTI) como importante reservatório de microrganismos patogênicos, visto que os equipamentos e materiais desse setor comportam bactérias multirresistentes responsáveis por diversas IH (Rocha, 2017). Essa resistência está relacionada à utilização de forma inadequada de antimicrobianos que favorecem mudanças genéticas nas bactérias, sendo a principal a produção de enzimas capazes de inativar a função de determinados antibióticos (Araújo et al., 2017).

Geralmente as IHs propagam-se através de contaminação cruzada, através da transferência de patógenos das mãos dos profissionais de saúde para os pacientes. Estudos realizados apontam a presença de bactérias causadoras de infecções nas mãos e anéis desses profissionais (Fracarolli \& Marziale, 2019). Além disso, as superfícies e objetos próximos ao paciente comportam bactérias e outros microrganismos patogênicos, que propiciam a contaminação através do contato sem a devida higienização das mãos e desses objetos inanimados, conforme mostra uma análise microbiológica de uma UTI adulto do Paraná realizado por Souza et al., (2019).

Um exemplo de objeto que pode atuar como reservatório de microrganismos indesejáveis é o colchão hospitalar, tendo em vista que está em contato direto com o paciente e geralmente por um longo período. Com isso, esse objeto pode reter sujidades e favorecer a existência de bactérias causadoras de infecções (Mahl \& Rossi, 2017).

Diante da importância do ambiente como reservatório e como possível fonte de transmissão de microrganismos que causam IHs, o objetivo deste trabalho foi isolar e identificar as bactérias presentes nas macas de duas enfermarias de um Hospital Universitário de Pernambuco e analisar o perfil de resistência antimicrobiana destas.

\section{Metodologia}

O presente trabalho consiste em estudo descritivo-exploratório com abordagem quantitativa. O experimento foi realizado no período de agosto a outubro de 2019, onde foram analisadas as superfícies de um total de 60 macas de duas enfermarias, a Sala de Observação da Urgência e Emergência e a Sala de Emergência de um Hospital Universitário de Pernambuco, que apresenta perfil assistencial geral de média e alta complexidade à comunidade adulta, com dimensionamento dos serviços assistenciais e de ensino e pesquisa. É considerada referência em traumas, politraumas, neurocirurgia, ortopedia clínica geral e médica.

A coleta das amostras foi realizada nas seguintes superfícies das macas: a) Grade esquerda da maca; b) Grade direita da maca; c) Centro superior da maca (altura da cabeça) e d) Centro inferior da maca (altura dos pés).

As amostras das superfícies foram coletadas utilizando-se moldes de papel filtro de área de $4 \mathrm{~cm}^{2}$ para delimitar a área analisada e swabs estéreis embebidos em solução salina ( $\mathrm{NaCl} 0,9 \%)$. Cada área foi amostrada em 2 pontos diferentes, aleatoriamente. Após a passagem do swab, nas superfícies, eles foram armazenados em tubo contendo 5 mL meio líquido Brain Heart Infusion (BHI) (BD, 2003). Em seguida, as amostras foram transportadas para o Laboratório de Análises Clínicas/ Setor Microbiologia, onde foram realizadas as análises microbiológicas. 
No laboratório, os caldos BHI foram incubados a $37^{\circ} \mathrm{C}$ por 24 horas na estufa bacteriológica. Para isolamento dos microrganismos, as amostras foram semeadas em Ágar Sangue (AS) e incubadas a $37^{\circ} \mathrm{C}$ por 24 horas. Após o período de incubação, nos meios em que houve crescimento bacteriano realizou-se a coloração de Gram (Freitas \& Picoli, 2007) e as provas bioquímicas para a identificação de cada espécie. Para identificação dos cocos gram positivos foi utilizado a prova de catalase. Para catalase positiva, realizou-se a prova de coagulase, já para a catalase negativa, utilizou-se o Kit para Enterococcus, bacitracina e optoquina para identificar as espécies. Para a identificação dos bastonetes gram negativos foram utilizados os kits para identificação de Enterobactérias e/ou de Não Fermentadores, conforme as instruções do fabricante.

As bactérias identificadas foram submetidas ao antibiograma pelo método de Ágar Difusão em Disco conforme as instruções CLSI (2019) e a escolha dos antimicrobianos foram conforme o microrganismo isolado.

Os dados foram digitados em arquivos no formato de planilhas e gráficos nos softwares Excel e Word da Microsoft Office versão 7.0 para Windows e realizada análise descritiva com valores absolutos e em percentuais. Para a comparação da quantidade das bactérias isoladas nas salas estudadas foi utilizado o software GraphPad Prism, através do teste não-paramétrico de Mann-Whitney, com um intervalo de confiança de 95\%.

\section{Resultados}

Após análise microbiológica das superfícies das macas da Sala de Observação da Urgência e Emergência, foi encontrado o total de 302 isolados bacterianos independente dos locais amostrados nas macas, sendo que 16 (5\%) podem ser consideradas possíveis bactérias causadoras de infecções hospitalares, a saber: 3 isolados de Staphylococcus aureus, 3 de Klebsiella ozaenae, 3 de Enterococcus faecium, 2 de Acinetobacter baumannii, 2 de Klebsiella pneumoniae, 1 de Enterococcus hirae, 1 de Enterobacter cloacae e 1 de Streptococcus cristatus (Figura 1). As demais bactérias isoladas encontram-se no grupo dos Staphylococcus coagulase negativa (100 isolados) e nas bactérias do ambiente (186 isolados), assim chamadas no presente estudo, pois não foram identificadas pelas provas bioquímicas utilizadas na rotina de identificação de bactérias de interesse clínico e possuíam morfologia de bactérias presentes no ambiente, sugestivo de bacilos gram-positivos. 
Figura 1: Espécies bacterianas possíveis causadoras de IH isoladas nas superfícies das macas da Sala de Observação da Urgência e Emergência de um Hospital Universitário de Pernambuco.

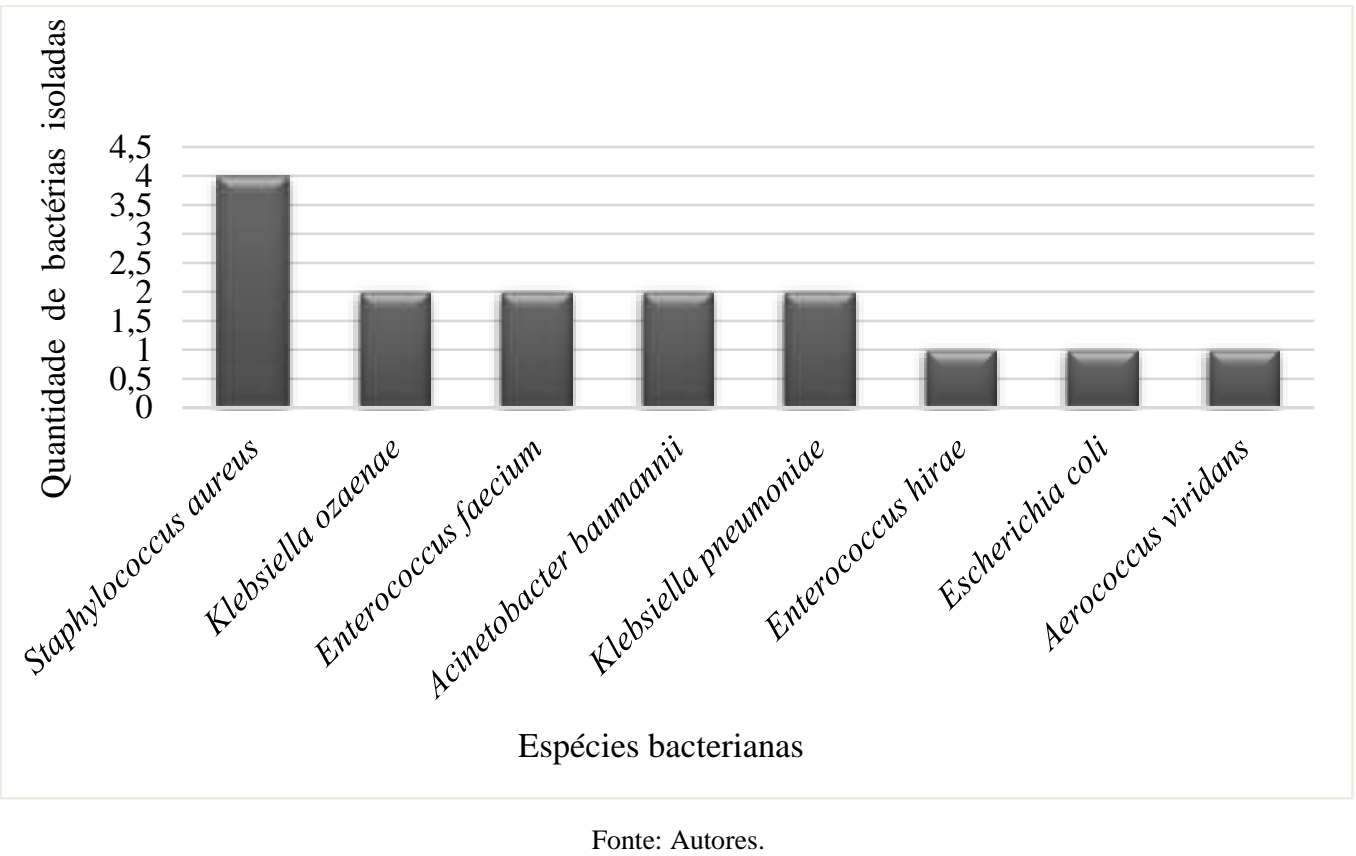

Em relação às bactérias isoladas na Sala de Emergência, independente dos locais amostrados nas macas, foram encontradas 260 isolados bacterianos, sendo que 16 (6\%) podem ser consideradas possíveis bactérias causadoras de infecções hospitalares, a saber: 4 isolados de Staphylococcus aureus, 2 de Klebsiella ozaenae, 2 de Enterococcus faecium, 2 de Acinetobacter baumannii, 2 de Klebsiella pneumoniae, 1 de Enterococcus hirae, 1 de Escherichia coli, 1 de Providencia stuarti e 1 de Aerococcis viridans (Figura 2). O restante das bactérias isoladas encontra-se no grupo dos Staphylococcus coagulase negativa ( 84 isolados) e nas bactérias do ambiente (160 isolados).

Figura 2: Espécies bacterianas possíveis causadoras de IH isoladas nas superfícies das macas da sala da Emergência de um Hospital Universitário de Pernambuco.

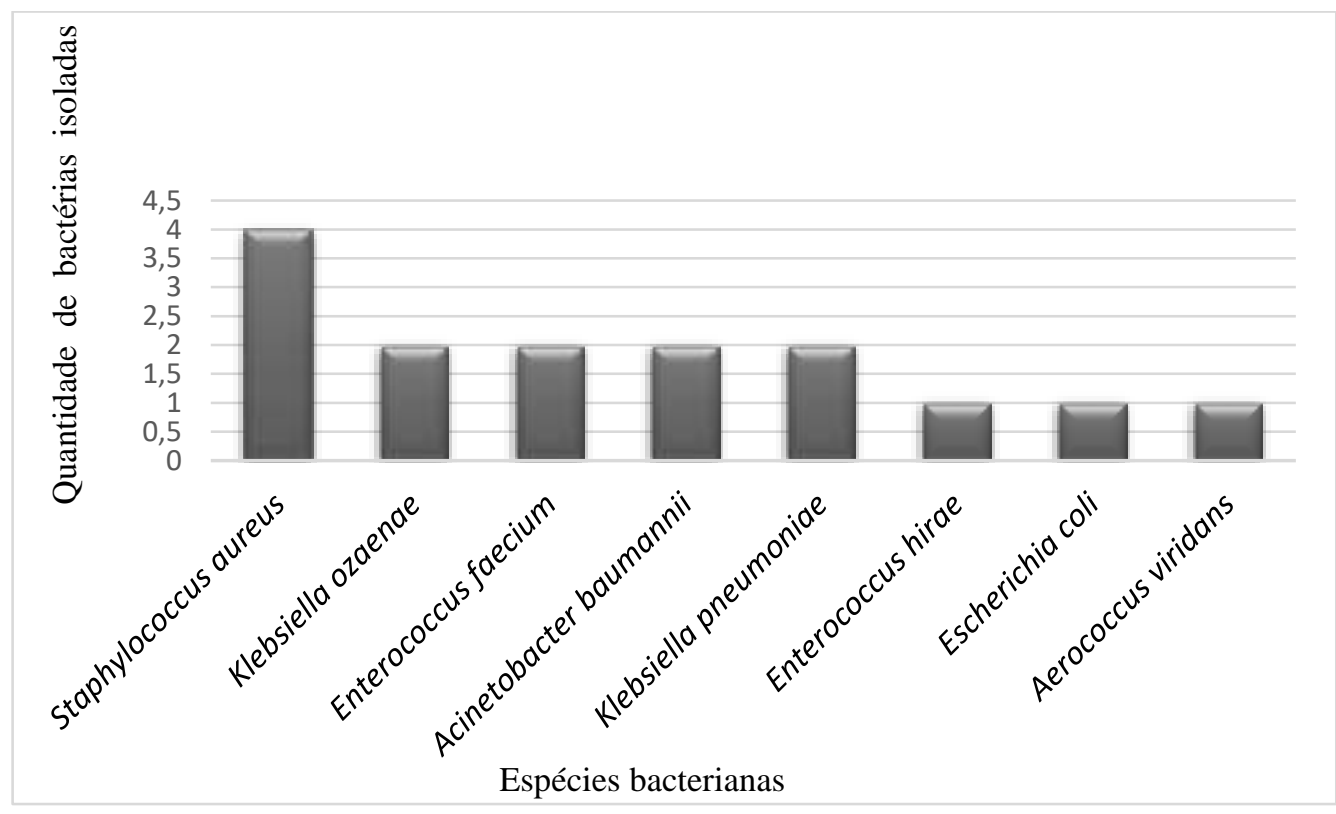

Fonte: Autores. 
Quando comparado a quantidade de bactérias isoladas e também as possíveis bactérias causadoras de infecções hospitalares da Sala de Observação da Urgência e Emergência com as isoladas na Sala da Emergência não foi verificado diferença significativa ( $\mathrm{p}=0,87$ e $\mathrm{p}=0,82$, respectivamente).

Em relação ao perfil de sensibilidade das espécies bacterianas gram negativas encontradas, Acinetobacter baumannii isolados da Sala de Observação da Urgência e Emergência foram 100\% sensíveis a todos os antibióticos testados, a saber: amicacina, ampicilina + sulbactam, cefepima, ceftazidima, ceftriaxona, ciprofloxacino, gentamicina, imipenem, levofloxacino, meropenem, piperacilina + tazobactam e sulfametoxazol + trimetoprima. Já as cepas da Sala de Emergência apresentaram-se 50\% resistentes a amicacina, ampicilina + sulbactam, cefepima, ceztazidima, ceftriaxona, ciprofloxacino, gentamicina, imipenem, levofloxacino, meropenem, piperacilina + tazobactam e 100\% sensíveis somente a sulfametoxazol + trimetoprima.

K. pneumoniae isoladas nas macas da Sala de Observação da Urgência e Emergência, apresentaram-se 100\% sensíveis à amicacina, imipenem, meropenem, tigeciclina e sulfametoxazol + trimetoprima, 50\% resistentes a cefoxitina, ciprofloxacino, ertapenem e gentamicina; e 100\% resistentes a ampicilina, ampicilina + sulbactam e cefepima. Na sala da Emergência a resistência foi encontrada apenas para o antibiótico ampicilina, o restante dos antibióticos testados foram todos sensíveis.

Para Klebsiella ozaenae observou-se que as da Sala de Observação da Urgência e Emergência foram 100\% sensíveis aos seguintes antibióticos: amicacina, ampicilina, ampicilina + sulbactam, cefepima, cefoxitina, ceftriaxona, ciprofloxacino, ertapenem, gentamicina, imipinem, meropenem, piperacilina + tazobactam, tigeciclina e sulfametoxazol + trimetoprima e 66,66\% resistentes a cefazolina. Já os isolados K. ozaenae da Sala da Emergência apresentaram-se 100\% resistentes a ampicilina e 50\% resistentes a ertapenem. Para o restante dos antibióticos como, amicacina, ampicilina + sulbactam, cefepima, cefoxitina, ceftriaxona, ciprofloxacino, gentamicina, imipinem, meropenem, piperacilina + tazobactam, tigeciclina, sulfametoxazol + trimetoprima os isolados foram $100 \%$ sensíveis.

Enterobacter cloacae, isolada apenas nas macas da sala de Observação da Urgência e Emergência, mostrou-se sensível a amicacina, ertapenem, imipenem, meropenem e piperacilina + tazobactam; intermediária a tigeciclina e resistente a ampicilina, ampicilina + sulbactam, cefazolina, cefepima, cefoxitina, ceftriaxona, ciprofloxacino, gentamicina, levofloxacino e sulfametoxazol + trimetoprima.

Para Escherichia coli, a qual foi isolada somente nas macas da Sala da Emergência, pode-se observar resistência apenas ao antibiótico sulfametoxazol + trimetoprima. Aos demais antibióticos testados, amicacina, ampicilina, ampicilina + sulbactam, cefepima, cefoxitina, ceftriaxona, ciprofloxacino, ertapenem, gentamicina, imipenem, meropenem, piperacilina + tazobactam, tigeciclina e sulfametoxazol + trimetoprima ela foi sensível.

O isolado de Providencia stuartii também encontrado somente nas macas da Sala de Emergência foi sensível aos antibióticos amicacina, cefepima, cefoxitina, ertapenem, meropenem, piperacilina + tazobactam e sulfametoxazol + trimetoprima; intermediário a ceftriaxona; e resistente a ampicilina, ampicilina + tazobactam, cefazolina, ciprofloxacino, gentamicina, imipinem, levofloxacino e tigeciclina.

Em relação às bactérias gram positivas, o perfil observado para Enterococcus, independente da sala e da espécie, foi de $100 \%$ de sensibilidade para todos os antibióticos testados, a saber: ampicilina, daptomicina, linezolida, penicilina e vancomicina.

Os isolados de Staphylococcus aureus, encontrados nas macas da Sala de Observação da Urgência e Emergência, apresentaram $100 \%$ de sensibilidade para ceftarolina, daptomicina, linezolida, moniciclina, oxacilina, rifampicina, tigeciclina, sulfametoxazol + trimetoprima e vancomicina; resistência de 66,66\% para clindamicina e eritromicina e 100\% de resistência para ampicilina e penicilina. Na Sala de Emergência, foi observado um perfil de resistência de 33,33\% para clindamicina, 
eritromicina, sulfametoxazol + trimetoprima e oxacilina. Em relação ao restante dos antibióticos testados, ceftarolina, daptomicina, linezolida, moniciclina, rifampicina, tigeciclina e vancomicina, os isolados foram $100 \%$ sensíveis.

O isolado de Streptococcus cristatus apresentou resistência a sulfametoxazol + trimetoprima e tetraciclina e sensibilidade à vancomicina, clindamicina, ceftriaxona, cloranfenicol, cefepima, levofloxacino e eritromicina.

Para Aerococcus viridans foi observado resistência para sulfametoxazol + trimetoprima e eritromicina. Para os antibióticos clindamicina, cefepima, ceftriaxona, levofloxacino, tetraciclina, vancomicina e cloranfenicol o isolado foi sensível.

\section{Discussão}

Barros et al., (2019) apontam a relevância que o ambiente hospitalar desempenha com relação às IHs, dado que seus objetos e superfícies são reservatórios de possíveis microrganismos patogênicos. Acrescentam ainda que as mãos dos profissionais de saúde são importantes transmissores e favorecem o processo de contaminação, que acontece durante a prestação de assistência aos pacientes.

Tendo em vista a diminuição dessas infecções, pesquisas realizadas na Carolina do Norte (EUA) analisaram as superfícies que são constantemente manipuladas por profissionais de saúde, entre elas superfícies das camas, e apontaram que estes equipamentos são ambientes favoráveis para reservar e transmitir microrganismos patogênicos relacionados às IH (Rocha 2017). No presente trabalho analisou-se a superfícies de macas e pode-se observar que elas também se comportam como reservatórios de microrganismos patogênicos.

Em relação a prevalência e a identificação das espécies, um estudo realizado por Wisniewski (2020) para identificar os microrganismos patogênicos em diferentes superfícies de uma UTI, isolou e identificou 11 espécies bacterianas, sendo que quatro delas também foram identificadas no presente estudo, a saber Staphylococcus aureus, Klebsiella pneumoniae, Acinetobacter baumannii e Escherichia coli. Ainda de acordo com este autor, a desinfecção dos setores e objetos hospitalares e higienização das mãos são essenciais para redução das taxas de infecção hospitalar.

Um trabalho realizado por Amador et al., (2018) verificou a prevalência do Staphylococcus aureus em 26 superfícies de uma UTI do Paraná, constatando a sua presença em 50\% das superfícies, sendo que nas grades das camas houve maior frequência desta espécie bactéria. Além disso, estes autores afirmam que essa bactéria é uma das mais associadas à IHs. Em conformidade a isso, ressalta-se a importância da análise das superfícies das macas hospitalares, dado que no presente estudo o Staphylococcus aureus também apresentou a maior incidência, isolado um total de 07 bactérias desta espécie.

Neste mesmo sentido, Araújo et al., (2017) desenvolveram um estudo em uma UTI, para constatar a presença de bactérias e definir o perfil de resistência desses microrganismos aos antibióticos utilizados. Das 50 amostras analisadas, 36 apresentaram crescimento bacteriano, sendo isolados Staphylococcus aureus, Staphylococcus coagulase negativa e Staphylococcus epidermidis. Dentre as superfícies analisadas, mais uma vez a grade da cama apresentou o maior crescimento de Staphylococcus aureus multiresistente, associando-se também este resultado possivelmente ao contato frequente das mãos contaminadas da equipe de saúde e visitantes, o que pode estar relacionado ao fato desse microrganismo também ser o mais encontrado nos resultados do presente trabalho.

Outras bactérias de destaque no presente estudo foram Klebsiella ozaenae e Enterococcus faecium, totalizando cinco de cada espécie, quando considerado a análise das macas das duas salas. Uma pesquisa realizada por Freitas et. al., (2020) destacou a presença da primeira como uma das principais bactérias patogênicas encontradas em bandejas de medicação utilizadas pela equipe de enfermagem. A segunda, está associada a uma quantidade significativa de infecções que acometem o homem e apresenta grande susceptibilidade ao desenvolvimento de resistência (Santos et al., 2021). 
Os antibióticos compreendem diferentes mecanismos de ação, o que faz com que as bactérias desenvolvam diferentes mecanismos de resistência, que geralmente estão atrelados a modificações na permeabilidade da membrana e a capacidade de inativar a função de determinados antibióticos (Lima et al., 2017).

Em relação ao perfil de sensibilidade das espécies bacterianas gram negativas encontradas, Acinetobacter baumannii isolados na sala da Emergência do presente estudo, apresentou resistência a diferentes classes de antibióticos. Uma análise realizada nos objetos e mãos de profissionais de uma UTI de um hospital público brasileiro as cepas de A. baumannii apresentaram resistência a todos os antibióticos testados (Lima et al., 2019).

A. baumannii é um patógeno oportunista de grande relevância e desenvolve rapidamente mecanismos de resistência antimicrobiana por meio da capacidade de suportar a dessecação, formar biofilmes, e apresentar genoma plástico com grande capacidade de mutação ao ser exposto a adversidades e estresse (Harding et al., 2018). Outras formas de resistência são definidas por Cangussu (2020) como aquisição de material genético móvel, capacidade de degradação de enzimas, e principalmente resistência a beta-lactâmicos por meio da síntese de beta-lactamase. Além disso, apresentam resistência à penicilinas, cefalosporinas e aztreonam por expressão gênica de $\beta$-lactamases de espectro estendido (ESBL), entre outras formas de resistência.

Os isolados Klebsiella pneumoniae foram resistentes parcialmente à cefoxitina, ciprofloxacino, ertapenem e gentamicina e totalmente resistentes a ampicilina, ampicilina + sulbactam e cefepima. Essa bactéria é considerada uma das três de maior perigo a nível mundial pela Organização Mundial da Saúde (OMS) quando desenvolvem resistência a carbapenêmicos (antibióticos de terceira geração) como o ertapenen e apresenta capacidade de acumular resistência a diversas drogas, através de um envelope celular com várias camadas (Amin et al., 2020). Outros mecanismos de resistência são a expressão de bombas de influxo e efluxo, e modificações nos canais de porinas, presentes em conjunto ou de forma isolada conferem resistência a variados antimicrobianos, no entanto seu maior e mais preocupante método de resistência é a síntese de carbapenemases (Bernardo, 2020).

O isolado de Escherichia coli no presente estudo, demonstrou resistência apenas ao antibiótico sulfametoxazol + trimetoprima. E. coli é a maior causadora de ITU podendo apresentar como mecanismo de resistência uma modificação cromossômica, que pode modificar sua membrana celular e consequentemente sua permeabilidade (Kerhkoff et al., 2020). Para realizar sua função, o antibiótico precisa penetrar a célula bacteriana, atravessar sua parede e membrana celular e atingir o seu foco de ação, quando isso não é possível esse microrganismo adquire resistência a esse fármaco (Oliveira et al., 2014). Ainda de acordo com este autor, E. coli pode desenvolver a capacidade de sintetizar bombas multirresistentes, que permite o bombeamento do antibiótico para o exterior da célula antes dele realizar sua função. Essas bactérias recebem os genes codificadores dessas bombas por conjunção com plasmídeos e tornam-se resistentes a vários fármacos.

O isolado de Providencia stuartii demonstrou sensibilidade a todos os antibióticos testados, apesar disso, de acordo com Pereira (2016) o P. stuartii tem aumentado seu perfil de resistência devido ao uso de antibióticos de amplo aspecto, tornando-se mais frequente nas infecções hospitalares e aumentado o índice de mortes em pacientes debilitados de uma UTI de um hospital de referência de Fortaleza- CE.

A cepa de Enterobacter cloacae demonstrou resistência a diversas classes de antibióticos e está relacionado a infecções como endocardite, osteomielite e pneumonia e vem desenvolvendo mecanismos de resistências. A ampliação do uso das $\beta$-lactamases de espectro estendido (ESBL) e cabarpanemases possibilitou E. cloacae torna-se a terceira causa de IH causadas por Enterobacteriaceae (Vieira et al., 2020).

Com relação aos isolados gram positivo, o Staphylococcus aureus mostrou-se resistente a diversas classes de antibióticos testados. Inicialmente, essa bactéria sintetizava enzimas $\beta$-lactamases, tornando-se resistente aos $\beta$-lactâmicos. A partir disso, vários mecanismos passaram a desenvolver-se, e atualmente já existem cepas de bactérias que são resistentes a 
todas as drogas existentes, inclusive tornaram-se resistentes oxacilina (MRSA) que é um dos antibióticos de escolha para tratar essas infecções (Mendes et al., 2020).

Essa bactéria é responsável por diversas infecções, além disso, apresenta mecanismos que favorecem sua multirresistência como aquisição de genes resistentes e/ou mutações, no primeiro caso o $S$. aureus destrói ou inativa a função do antibiótico por meio de genes adquiridos de bactérias da mesma espécie, ou de forma menos comum de outras espécies. No segundo ocorre devido à modificação do local de ação do antimicrobiano (Cussolim et al., 2021).

Este microrganismo apresenta outras formas de resistência, são elas superprodução de beta-lactamases, alterações na aptidão de ligar a PBPs e por último devido a alteração de uma proteína ligadora de penicilina chamada de PBP $2^{a}$ definida por meio o gene mecA. Quando este último é associado a resistência à meticilina impede o funcionamento de todos antibióticos $\beta$ lactâmicos atuais disponíveis no mercado e pode fornecer resistência às outras classes de fármacos (Mendes et al., 2020).

O isolado de Streptococcus cristatus apresentou resistência a sulfametoxazol + trimetoprima e tetraciclina, S. cristatus pode estar associado a infecções como meningite bacteriana, infecção do trato urinário, artrite séptica e de forma mais rara a endocardite (Orati et al., 2014).

A resistência antimicrobiana implica em diversos problemas no ambiente hospitalar, tais como prolongamento da internação, restrição das possibilidades do uso de determinadas medicações e o aumento na quantidade de drogas para o tratamento do paciente e controle das IHs (Gil et al., 2018). Além disso, vem representando um grande perigo, pois tornaram se prevalentes em infecções comunitárias e simultaneamente a produção de novos antibióticos para combater essas bactérias é lenta e limitada, gerando problemas para a saúde pública (Carvalho et al., 2021).

Algumas medidas relacionadas ao ambiente são fundamentais para redução da IH e fazem parte do programa de segurança do paciente, como limpeza e desinfecção de objetos e superfícies hospitalares, adesão a recomendações de isolamentos, higienização efetiva das mãos e vigilância contínua em situações excessivas (Napoles, 2020).

A ausência ou falhas nesses processos favorecem a permanência de bactérias nas superfícies hospitalares e estudo recente aponta que apesar do conhecimento sobre a importância dessas medidas, a adesão à higienização das mãos e objetos é baixa e está relacionada a cargas exaustivas de trabalho e condições desse ambiente (Gil et al., 2018).

\section{Conclusão}

O presente estudo permitiu, por meio das análises microbiológicas das macas, isolar e identificar possíveis bactérias causadoras de infecção hospitalar, tais como Acinetobacter baumannii, Klebsiella pneumoniae, Staphylococcus aureus, Enterobacter cloacae e Providencia stuartii. Foi verificado elevados perfis de resistência e em algumas espécies observou-se resistência total a determinados antibióticos e até mesmo multirresistência.

Conhecer essa microbiota favorece a implementação de ações a serem realizadas pela equipe de higienização do hospital e demais colaboradores que manipulam os leitos durante a assistência prestada ao paciente. Ressalta-se também a importância de conscientização dos profissionais quanto à higienização das mãos para assim reduzir os índices de infecção cruzada, disseminação de patógenos resistentes e consequentemente das infecções hospitalares na instituição.

\section{Referências}

Amador, J. F. S., Basso, L. C., \& Vieira, S. L. V. (2018). Prevalência de Staphylococcus aureus em superfícies de unidade de terapia intensiva. Arquivos do MUDI, 22(2), 4-6.

Amin, C. E., dos Santos, D. P., Linhaus, F. K., Freitas, I. M., dos Santos Rodrigues, J., \& Paulo, M. S. L. (2020). Fatores determinantes na infecção hospitalar por klebsiella pneumoniae resistente a carbapenêmicos. Brazilian Journal of Health Review, 3(5), 14322.

Araujo, M. Q., Poletto, K. Q. \& Bessa, N. G. (2017). Perfil de resistência bacteriana em fômites de UTI em hospital público do Estado do Tocantins. REVISTA CEREUS, 9(2), 129- 134. 
Barros, F. E., Soares, E., de Oliveira Teixeira, M. L., \& da Silva Castelo Branco, E. M. (2019). Controle de infecções a pacientes em precaução de contato. Journal of Nursing UFPE/Revista de Enfermagem UFPE, 13(4), 1082.

Bernardo, A. Fatores de Risco para Colonização/Infeção por Klebsiella pneumoniae resistente a carbapenemos. 2020. 55f. Dissertação (de mestrado), Clínica Universitária de Doenças Infeciosas, Universidade de Lisboa, 2020.

Cangussu, E. W. S. (2020). Importância do Acinetobacter baumannii no ambiente hospitalar. Journal of Biotechnology and Biodiversity, 8(1), 041-046.

Carvalho, J. J. V., Boaventura, F. G., da Silva, A. D. C. R., Ximenes, R. L., Rodrigues, L. K. C., de Almeida Nunes, D. A., \& de Souza, V. K. G. (2021). Bactérias multirresistentes e seus impactos na saúde pública: Uma responsabilidade social. Research, Society and Development, 10(6), 3.

Costa, M., Rodrigues, G. M. C., Gomes, W. M., Júnior, A. A. R., \& Cardoso, F. M. N. (2019). Principais micro-organismos responsáveis por infecções relacionadas à assistência em saúde (iras) em UTIs: uma revisão integrativa. Revista Eletrônica da Faculdade de Ceres, 8(1), 30-30.

Cussolim, P. A., \& Junior, A. S. (2021). Mecanismos de resistência do Staphylococcus aureus a antibióticos. Revista faculdades do saber, 6(12), 831-843.

Silva, E. P., de Almeida Carreiro, M., \& Gomes, R. C. (2016). Metodologia para a identificação de Staphylococcus sp. na superficie do colchão da maca no pronto socorro. Revista Pró-UniverSUS, 7(3), 15-19.

Freitas, C. G. D. S., Staudt, K. J., Khün, K. H., Alves, I. A., \& Meneghete, M. C. (2020). Prevalência de microrganismos em bandejas utilizadas pela enfermagem na administração de medicamentos em ambiente hospitalar. Revista interdisciplinar em ciências da saúde e biológicas-RICSB, 3(2), 24-34.

Sousa, M. A. S., Nascimento, G. C., Bim, F. L., de Oliveira, L. B., \& da Silva Oliveira, A. D. (2017). Infecções hospitalares relacionadas a procedimentos invasivos em unidades de terapia intensiva: Revisão integrativa. Revista Prevenção de Infeç̧ão e Saúde, 3(3), 50.

Santos, M. A., de Paiva, I. C., \& da Silva Andrade, E. G. (2021). Enterococcus resistente a vancomicina (vre): perfil geral. Revista JRG de Estudos Acadêmicos, 4(8), 127-139.

Fracarolli, I.F. L.; Marziale, M. H. P. Caracteríticas microbiologicas de las mãos ey anillos de trabajadores de saludv- revisión integrativa. Ciencia y enfermeria, v 25, p. 00, 2019.

Freitas, V. R., \& Picoli, S. U. (2007). A coloração de Gram e as variações na sua execução. Newslab, 82, 124-128.

Gil, A. C., Bordignon, A. P. P., de Castro, E. A. R., Castro, S. T., Rafael, R. D. M. R., \& Pereira, J. A. A. (2018). Avaliação microbiológica de superfícies em terapia intensiva: reflexões sobre as estratégias preventivas de infecções nosocomiais [Microbiological evaluation of surfaces in intensive care: thinking about nosocomial infection prevention strategies][Evaluación microbiológica de superficies en cuidados intensivos: reflexiones sobre las estrategias preventivas de infecciones nosocomiales]. Revista Enfermagem UERJ, 26, 26388.

Harding, C. M., Hennon, S. W., \& Feldman, M. F. (2018). Uncovering the mechanisms of Acinetobacter baumannii virulence. Nature Reviews Microbiology, 16(2), 91-102.

Humphries, R. M., Hindler, J. A., Shaffer, K., \& Campeau, S. A. (2019). Evaluation of ciprofloxacin and levofloxacin disk diffusion and Etest using the 2019 Enterobacteriaceae CLSI breakpoints. Journal of clinical microbiology, 57(3), e01797-18.

Kerhkoff, J. S., Oliveira, K. S., de Freitas, R. F., de Sá Teles, R., \& Silva, W. A. 2020. Análise da frequência e perfil de sensíbilidade dos agentes etiológicos de infecções do trato urinário em um laboratório particular. Cuiabá-MT, 2020.

Bernardo, A. Fatores de Risco para Colonização/Infeção por Klebsiella pneumoniae resistente a carbapenemos. 2020. 55f. Dissertação (de mestrado), Clínica Universitária de Doenças Infeciosas, Universidade de Lisboa, 2020.

Leoncio, J. M., Almeida, V. F. D., Ferrari, R. A. P., Capobiango, J. D., Kerbauy, G., \& Tacla, M. T. G. M. (2019). Impact of healthcare-associated infections on the hospitalization costs of children. Revista da Escola de Enfermagem da USP, 53, 2.

Lima, C. C., Benjamim, S. C. C., \& Santos, R. F. S. D. (2017). Mecanismo de resistência bacteriana frente aos fármacos: uma revisão. CuidArte, Enferm, 105113.

Lima, L. K. O. L., Pinto, J. C. G., Misael, L. S., Castro, R. B., Coelho, D. D., Benevides, D. V. L., \& Sousa, E. R. M. (2019). Avaliação da contaminação por Acinetobacter spp. em uma unidade de terapia intensiva. Rev. epidemiol. controle infecç, 241-247.

Mahl, S., \& ROSSI, E. (2017). Susceptibilidade antimicrobiana de bactérias isoladas de colchões hospitalares. Revista Brasileira de Análises Clínicas, 49(4), 371-375.

Mendes, F. L. R., Carvalho, E. M., Abrantes, J. A., \& Nogueira, J. M. D. R. (2020). Buscando novos antimicrobianos: avaliação da atividade antibacteriana de extratos de Eugenia brasiliensis. Rev. bras. anal. clin, 228-234.

Michelin, A. F., \& Fonseca, M. R. C. C. D. (2018). Perfil epidemiológico das infecções hospitalares na unidade de terapia intensiva de um hospital terciário. Nursing (Säo Paulo), 2037-2041.

Napoles, K. M. N. Medidas de controle para disseminação de bactérias multiresistentes. Limpeza e desinfecção dos equipamentos médicos hospitalaresEnfermagem (2020). Inovação, Tecnologia e Educação em Saúde 24 (1), 334.

Oliveira, A. L. D., Soares, M. M., Santos, T. C. D., \& Dos Santos, A. D. R. I. A. N. A. (2014). Mecanismos de resistência bacteriana a antibióticos na infecção urinária. Revista UNINGÁ Review, 20(3), 69-70.

Orati, J. A., Amorim, A., Tardivo, M. T., Simão, C. J. G., de Araújo, D. S. S., \& Castro, N. A. M. (2014). Aerococcus Viridanscomo Agente Etiológico de Endocardite em Valva Nativa. Rev Bras Cardiol, 27(4), 286-288. 
Research, Society and Development, v. 10, n. 14, e20101421509, 2021

(CC BY 4.0) | ISSN 2525-3409 | DOI: http://dx.doi.org/10.33448/rsd-v10i14.21509

Pereira, S. C. (2018). Detecção de Klebsiella pneumoniae e providencia stuartii pan-resistentes em pacientes de unidades de terapia semi e intensiva de um hospital de referência em Fortaleza-CE. Journal of Infection Control, 7(3), 2-3.

ROCHA, I. V. Identificação de mecanismos de resistência antimicrobiana de bactérias Gram negativas prevalentes em superfícies e hemoculturas de unidades de terapia intensiva em Caruaru-PE. 2017. Dissertação (Mestrado em Biociências e Biotecnologia em Saúde) - Centro de Pesquisas Aggeu Magalhães, Fundação Oswaldo Cruz, Recife, 2017.

Souza, M. E. D., Ferreira, H., Zilly, A., Mattos, A. L. A. D., Pereira, L. S. G., \& Silva, R. M. M. D. (2019). Condições de desinfecção de superfícies inanimadas em unidades de terapia intensiva. Rev. pesqui. cuid. fundam. 951-956.

Vieira, P. M., Vieira, L. M., de Souza Macêdo, T. L., \& de Aragão, I. P. B. (2020). Endocardite infecciosa em cabo de marcapasso por Enterobacter cloacae: Relato de Caso. Revista de Saúde, 11(2), 33-38.

Wisniewski, G. V., Fiorin, T. M., \& Alves, I. A. (2020). Identificação e Avaliação do Perfil de Resistência de Bactérias Isoladas da Unidade de Terapia Intensiva de um Hospital da Região Noroeste do Rio Grande do Sul. Revista Interdisciplinar em Ciências da Saúde e Biológicas, 4(1), 11-23. 